\title{
Bitcoin and Venezuela's Unofficial Exchange Rate
}

\author{
Jackie Johnson $^{\dagger}$
}

\begin{abstract}
Using Bitcoin trading data in Venezuelan bolivars from the LocalBitcoins peerto-peer market place and using the theory of Purchasing Power Parity (PPP), Bitcoin, as a single universal asset, is substituted for the 'basket of goods' normally used in the PPP, allowing the estimation of the relationship between the Venezuelan bolivar and the United States dollar. In this analysis Bitcoin is used as a tool to enable the calculation of the bolivars to dollars unofficial exchange rate and consequently the implied inflation rate. Using Bitcoin's publicly available prices in this way enables a government's economic mismanagement to be identified more quickly than the typical approach of measuring changes in the Consumer Price Index. Venezuela is currently in crisis, which this approach identifies as a problem as far back as 2014, as official and unofficial exchange rates diverge and inflation rates increase yearly reaching an unbelievable $70,000 \%$ in 2018 alone.
\end{abstract}

\section{Introduction}

For a country in the grip of hyperinflation, the news that the Venezuelan Central Bank is printing more money only adds to the political turmoil and economic uncertainty within the country. ${ }^{1}$ This, together with crumbling infrastructure, food shortages and virtually no medical supplies has led to over three million Venezuelans leaving the country. ${ }^{2}$ For those remaining, protecting their wealth from erosion is a problem not easy to solve. For them, a stable alternative is hard to find. Although Venezuela is a gold-producing country, purchasing gold with bolivars is difficult and small amounts are not easy to purchase or sell. The United States (US) dollar is a reasonable alternative but the country is short of dollars to even import basic necessities. Fortunately, there is one other alternative, Bitcoin, a decentralised peer-to-peer (P2P) payment system proposed by Satoshi Nakamoto in $2008,{ }^{3}$ built to bypass traditional financial systems, outside of government control, which can be purchased in quantities as small as one satoshi ( 0.00000001 of a bitcoin). The advantage of Bitcoin is that it can also be purchased outside of Venezuela in any currency for Venezuelan residents to sell in Venezuela for bolivars, keeping pace with inflation. Although Bitcoin's fortune over 2017-2018 fluctuated, it has not lost as much value as the bolivar, which, at the time of writing, is almost worthless.

The aim of this paper is twofold: extrapolate from Venezuela's Bitcoin trading their unofficial exchange rate; and using this rate approximate Venezuela's inflation rate over the last five years, adding to the evidence of hyperinflation and economic mismanagement. Section 2 covers the role that Bitcoin plays at times of economic uncertainty and its help in determining unofficial exchange rates. The data used is detailed in Section 3 and the

${ }^{\dagger}$ J. Johnson (johnsonresearchperth@gmail.com) is principal researcher at Johnson Research, Perth. 
evaluation of three benchmark currencies, which are used in the calculation of Venezuela's unofficial exchange rate, are discussed in Section 4. Section 5 covers the determination of Venezuela's unofficial exchange rates and the implied inflation rates from 2014 to 2018. Concluding remarks are covered in Section 6.

\section{The Role of Bitcoin}

Much of the early discussion regarding Bitcoin focuses on whether it is or is not a currency. David Yermack concludes that it resembles a highly speculative instrument as it lacks the three basic characteristics of money: acting as a medium of exchange, a unit of account, and a store of value. ${ }^{4}$ If Bitcoin doesn't fulfill the requirements of money, then who is attracted to using it? Aaron Yelowitz and Matthew Wilson, using Google trend data to study Bitcoin's clientele, analyse its use by four interest groups: the technically competent able to profit from a complex financial instrument they understand at a technical level; investors/speculators looking for financial reward; those involved in illegal activities attracted by its anonymity; and Libertarians with a desire for no government oversight. They conclude that the technically competent and illegal activities drive the interest in Bitcoin. ${ }^{5}$ Jeremiah Bohr and Masooda Bashir add to this, finding that an individual's political views also drives interest in Bitcoin, as Bitcoin represents a payment system outside of government control. ${ }^{6}$

Robert Viglione also finds a political aspect to Bitcoin interest, not in relation to the trader's politics but the politics of the country of residence and likens the purchase of Bitcoin to buying a proxy for disaster insurance in countries where there is instability and economic mismanagement. ${ }^{7}$ This is supported by the work of Xin Li and Chong Alex Wang, who conclude that although during the early years of Bitcoin trading, activity is driven by speculation, as the market matures it reacts more to economic fundamentals and changes in economic conditions. ${ }^{8}$ Being able to easily and cheaply access the Bitcoin market provides an ideal opportunity to hold wealth at risk of erosion.

In countries where residents are under pressure from economic mismanagement, Bitcoin trading becomes critical. Two factors drive Bitcoin trading: one, there is pressure to purchase Bitcoin using local currency before it loses even more value; and two, there is a need to redeem for the local currency either past purchases or purchases made outside the country by friends/family, enabling residents to cope with rising prices. This results in an increase in Bitcoin trading in the local currency.

Gina Pieters and Sofia Vivanco find that the Bitcoin implied exchange rate and the official rate can differ, pointing to the existence of an active black market exchange rate which in turn can expose the inaccuracy of official exchange rates. ${ }^{9}$ Pieters furthermore notes the difficulty in obtaining accurate unofficial exchange rates. ${ }^{10}$ Pointing out that Bitcoin can bypass restrictions on the acquisition of foreign currency, at the same time as taking advantage of trading at an alternative to official, potentially manipulated, exchange rates.

In fact, using Bitcoin's daily trading prices allows the construction of a meaningful alternative to official exchange rates. Consequently, any reporting bias can be negated as daily Bitcoin prices are made public and can be easily observed. As Bitcoin trades all day, every day, unofficial rates can be calculated at any time. Significant differences between market and official exchange rates may signal fundamental economic mismanagement. Nowhere is economic mismanagement more obvious than in Venezuela. 


\section{Data}

Although the behaviour of the Venezuelan bolivar is the focus of this study, Bitcoin trading data for two other South American currencies, the Brazilian real and the Argentinian peso, are also collected. Added to this is the United Kingdom's (UK) pound sterling, which is used as a reference for trading in a market with no unofficial exchange rate. Bitcoincharts.com is used as the source of Bitcoin's daily trading data. As the only available data for the Venezuelan bolivar is trading on LocalBitcoins, the real, peso and pound sterling data are also collected for this P2P market place. For each trading day Bitcoincharts.com provides:

(1) opening, closing, highest and lowest prices;

(2) total number of bitcoins traded, their value in local currency; and

(3) a daily weighted bitcoin price calculated by weighting the individual bitcoin prices paid, by the proportion of bitcoins traded at that price during the day. This minimizes the impact of very small trades at very high prices.

Table 1 details the period of daily trading data used. The starting date of 1 January 2014 is chosen as trading in the Venezuelan bolivar is too intermittent in 2013 to be useful. The ending date of 31 December 2018 is limited by data availability on Bitcoincharts.com.

Table 1. LocalBitcoins Daily Trading Data for Venezuela, Brazil, Argentina and the United Kingdom

\begin{tabular}{ccccc}
\hline Country & Currency & Start Date & End Date & $\begin{array}{c}\text { Number of } \\
\text { Trading Days }\end{array}$ \\
\hline Venezuela & Bolivar fuerte (VEF) & 29 Jan 2014 & 19 Aug 2018 & 1,496 \\
Venezuela & Bolivar soberano (VES) & 20 Aug 2018 & 31 Dec 2018 & 133 \\
Brazil & Real & 1 Jan 2014 & 31 Dec 2018 & 1,758 \\
Argentina & Peso & 1 Jan 2014 & 31 Dec 2018 & 1,773 \\
UK & Pound Sterling & 1 Jan 2014 & 31 Dec 2018 & 1,825 \\
\hline
\end{tabular}

All official exchange rates are downloaded from fxtop.com and the Bitcoin Price Index (BPI) in US dollars from CoinDesk (https://www.coindesk.com/price/bitcoin) is used as Bitcoin's market price.

3.1 Trading Bitcoins on LocalBitcoins - Rather than buying and selling bitcoins through a Bitcoin exchange where traders need to wait until the market agrees with the price at which they are prepared to buy or sell, traders on LocalBitcoins can select from a range of currencies, alternative prices and payment methods but are limited to what is on offer.

LocalBitcoins is a market place where registered traders whether buying or selling, pay to advertise their bitcoin's selling or buying price, detailing their location, currency and payment method options. Non-registered traders, whether buying or selling choose from what is being offered by the registered traders. Although it is effectively two markets, one with registered sellers and unregistered buyers; the other with registered buyers and unregistered sellers, LocalBitcoins does not distinguish between them for reporting purposes and merely reports the price, volume and time of each transaction.

Table 2 is a snapshot of bolivar offerings taken from the LocalBitcoins website (https://localbitcoins.com/country/VE) on 5 February 2019, indicating the price and payment method at which bitcoins are available for purchase in bolivar soberano (VES), 
which replaced the bolivar fuerte (VEF) on 20 August 2018 at the rate of 1 VES to 100,000 VEF.

Registered sellers are identified by a username together with an indication of reputation: how many trades they have made and a satisfaction rating. Payment method can be almost anything; the LocalBitcoins website lists a number of alternatives, such as gift card codes, cash, bank transfers, Paypal and any other payment option agreed by the parties concerned. Interestingly in Venezuela the payment method appears to be limited to bank transfers with a specified bank, with an occasional preference for Western Union. An unregistered buyer chooses with whom to transact, depending on transaction size and payment option.

Table 2. Bitcoins for Sale by Registered Sellers listing Payment and Transaction Options:

LocalBitcoins, 5 February 2019

\begin{tabular}{lllccc}
\hline $\begin{array}{c}\text { Registered } \\
\text { Sellers }\end{array}$ & $\begin{array}{c}\text { Number of } \\
\text { Trades and } \\
\text { Reputation }\end{array}$ & $\begin{array}{c}\text { Payment } \\
\text { Method }\end{array}$ & $\begin{array}{c}\text { Bitcoin Price } \\
\text { (VES) }\end{array}$ & $\begin{array}{c}\text { Bitcoin Price } \\
\text { (VEF equivalent) }\end{array}$ & $\begin{array}{c}\text { Size of Trade } \\
\text { Available } \\
\text { (VES) }\end{array}$ \\
\hline Rihua & $500+, 100 \%$ & Bank: Provincial & $8,990,000$ & $899.000,000,000$ & $35,000-2,681,094$ \\
jats81 & $1000+, 100 \%$ & Bank: BOD & $9,000,000$ & $900,000,000,000$ & $10,000-90,000$ \\
realFTW & $500+, 100 \%$ & Bank: Provincial & $9,100,000$ & $910,000,000,000$ & $50,000-91,000$ \\
anderloyo & $100+, 100 \%$ & Bank: Provincial & $9,200,000$ & $920,000,000,000$ & $150,000-300,000$ \\
raizozunotrx & $1000+, 100 \%$ & Bank: Provincial & $9,329,500$ & $932,950,000,000$ & $50,000-2,150,000$ \\
perezdavid & $500+, 100 \%$ & Bank: Provincial & $9,350,000$ & $935,000,000,000$ & $100,000-6,247,648$ \\
\hline
\end{tabular}

On the purchase side are the registered buyers. They advertise their price and payment and transaction details. Unregistered sellers choose from what is available. Table 3 is a sample of the price range and transaction sizes available on the LocalBitcoins website on 5 February 2019.

Table 3. Bitcoins for Purchase by Registered Buyers, Payment and Transaction Options: LocalBitcoins, 5 February 2019

\begin{tabular}{llcccc}
\hline $\begin{array}{c}\text { Registered } \\
\text { Buyers }\end{array}$ & $\begin{array}{c}\text { Number of } \\
\text { Trades and } \\
\text { Reputation }\end{array}$ & $\begin{array}{c}\text { Payment } \\
\text { Method }\end{array}$ & $\begin{array}{c}\text { Bitcoin Price } \\
\text { (VES) }\end{array}$ & $\begin{array}{c}\text { Bitcoin Price } \\
\text { (VEF equivalent) }\end{array}$ & $\begin{array}{c}\text { Size of Trade } \\
\text { Available } \\
\text { (VES) }\end{array}$ \\
\hline gregrod29 & $1000+100 \%$ & Western Union & $9,511,444$ & $951,144,400,000$ & $600000-3000000$ \\
NASH2017 & $3000+100 \%$ & Bank: Mercantil & $9,300,000$ & $930,000,000,000$ & $3000000-7749514$ \\
mapd1985 & $100+100 \%$ & Bank:Bicentario & $9,050,000$ & $905,000,000,000$ & $1000000-3000000$ \\
johan1550 & $15000+100 \%$ & Bank: Mercantil & $8,950,000$ & $895,000,000,000$ & $70000-1050000$ \\
pedrorey10 & $1000+100 \%$ & Bank: Mercantil & $8,801,120$ & $880,112,000,000$ & $5000-103000$ \\
\hline
\end{tabular}

If unregistered sellers have a significant number of bitcoins to sell, it is unlikely that they will take what is offered but rather set themselves up as a registered seller, detailing their required price and payment method.

From Tables 2 and 3 it can be seen that there are a range of possible transaction prices, any of which can be chosen for the next transaction which may be above the BPI (premium) or below the BPI (discount). It is important to understand the likely premium or discount at 
which Venezuelan bolivars are sold, so any calculation of Venezuela's unofficial exchange rate can take this into account.

\section{The Method for Determining Adjustments for Venezuelan Trading}

According to the theory of purchasing power parity (PPP), the currencies of different countries can be compared using a 'basket of goods' approach. Two currencies are in equilibrium or at par when a basket of goods (taking into account the exchange rate) is priced the same in both countries. Normally, to enable a comparison of prices across countries that holds any type of meaning, a wide range of goods and services must be considered, but here Bitcoin can be used, a universal asset that allows the determination of potentially overvalued or undervalued currencies. In the case of Bitcoin, the unofficial exchange rate can be determined by comparing the price of bitcoins in the currencies of two countries. Using Bitcoin, in place of a 'basket of goods,' avoids issues, such as transport costs, import tariffs and government intervention. However, in this case, as Bitcoin's trading prices on LocalBitcoins are being used, it is essential to factor in any expected variation from the market price (BPI) when determining the unofficial exchange rate. I have previously found that the amount that traders pay for bitcoins, above the market price (premium) on the LocalBitcoins market place, is significantly higher than the premiums paid using a Bitcoin exchange. ${ }^{11}$

The UK bitcoin trading on LocalBitcoins is a good example of what you would expect with no currency black market. Exchange rate variations between banks and currency exchanges are a factor of institutional costs and do not constitute a black market. For the pound sterling, for each day $(i)$ the bitcoin price variation from the BPI is calculated as follows:

$$
V_{i}=\frac{W P_{i} / X R_{i}-B P I_{i}}{B P I_{i}} \times 100 \%
$$

where:

$V_{i}$ is the variation as a percentage above $(+\mathrm{ve})$ or below (-ve) the BPI day $i$,

$W P_{i}$ is the daily weighted bitcoin price for the relevant currency on day $i$,

$X R_{i}$ is the official exchange rate between the US dollar and the relevant currency on day $i$, and

$B P I_{i}$ is the Bitcoin price index on day $i$.

If the variation is positive, then bitcoins are sold at a premium. If negative, bitcoins have changed hands at a discount in relation to the BPI.

As can be seen in Table 4 (column 2), from 2014 through to the end of 2018 average daily variations for the UK's pound sterling are positive and premiums range from $+1.4 \%$ to $+3.8 \%$, a reflection of the small risk associated with $\mathrm{P} 2 \mathrm{P}$ transactions.

This does not mean that on every day bitcoins are sold at a premium to the market price, on some days the weighted price is below the BPI, but in the case of the UK on the majority of days $(71.8 \%-97.0 \%)$ the weighted average price is above the market. Table 4 includes these details.

Two South American currencies are also used to provide some guidance as to the appropriate premium to use when calculating Venezuela's unofficial exchange rate: the Argentinian peso and the Brazilian real. As can be seen in Table 4, over the 5 year period the Brazilian real has an average premium of $7 \%$ with over $84 \%$ of days with weighted prices 
above the BPI. The IMF classify the Brazilian real exchange rate as floating but Pieters views it more as a managed float. ${ }^{10}$ The average premiums paid for bitcoins do not indicate that the exchange rate is managed.

Table 4. Average daily premiums and the percentage of days at which weighted daily prices are above the BPI

\begin{tabular}{ccccccc}
\hline Year & $\begin{array}{c}\text { UK pound } \\
\text { sterling } \\
(\%)\end{array}$ & $\begin{array}{c}\text { Days above } \\
\text { the BPI } \\
(\%)\end{array}$ & $\begin{array}{c}\text { Brazilian } \\
\text { real } \\
(\%)\end{array}$ & $\begin{array}{c}\text { Days above the } \\
\text { BPI } \\
(\%)\end{array}$ & $\begin{array}{c}\text { Argentinian } \\
\text { peso } \\
(\%)\end{array}$ & $\begin{array}{c}\text { Days above } \\
\text { the BPI } \\
(\%)\end{array}$ \\
\hline 2014 & 2.92 & 82.1 & 10.35 & 92.5 & 47.20 & 100.0 \\
2015 & 3.80 & 97.0 & 6.06 & 92.4 & 47.95 & 100.0 \\
2016 & 3.23 & 96.7 & 7.22 & 98.4 & 3.39 & 84.9 \\
2017 & 2.67 & 82.5 & 7.81 & 88.2 & 9.13 & 96.7 \\
2018 & 1.40 & 71.8 & 3.46 & 84.1 & 8.09 & 97.0 \\
Avg. & 2.80 & & 6.98 & & $6.69^{*}$ & \\
\hline
\end{tabular}

*Averaged over the last three years

However, while calculating the Argentinian peso's variation to the BPI, it becomes obvious that it has had a similar problem to Venezuela (though somewhat smaller in size), of a significant difference between official and unofficial exchange rates, which their government dealt with on 18 December 2015. This is evident in Table 4 (columns 6 and 7) where it shows that the bitcoin premiums are over $47 \%$ in both 2014 and 2015 and the percentage of days over the BPI is $100 \%$. An unlikely scenario if the official exchange rate is accurate.

Using the average of Argentina's last three year's trading, a $+7 \%$ adjustment is used to calculate Argentina's unofficial exchange rate each day, as follows:

$$
U X R_{i}=W P_{i}(1-A d j) / B P I_{i}
$$

where:

$U X R_{i}$ is the unofficial exchange rate on day $i$,

$W P_{i}$ is the daily weighted bitcoin price for the relevant currency on day $i$,

$A d j$ is the expected adjustment for $\mathrm{P} 2 \mathrm{P}$ trading on LocalBitcoins, and

$B P I_{i}=$ BPI on day $i$.

This is a similar approach to that used by Jacob Smith, ${ }^{12}$ but as the trading prices are from the LocalBitcoins P2P market an adjustment is made to the daily prices. Fig. 1 shows Argentina's unofficial and official exchange rates from 2014 to 2018 with the adjustment to a floating exchange rate on 18 December 2015. 
LEDGER VOL 4 (2019) 108-120

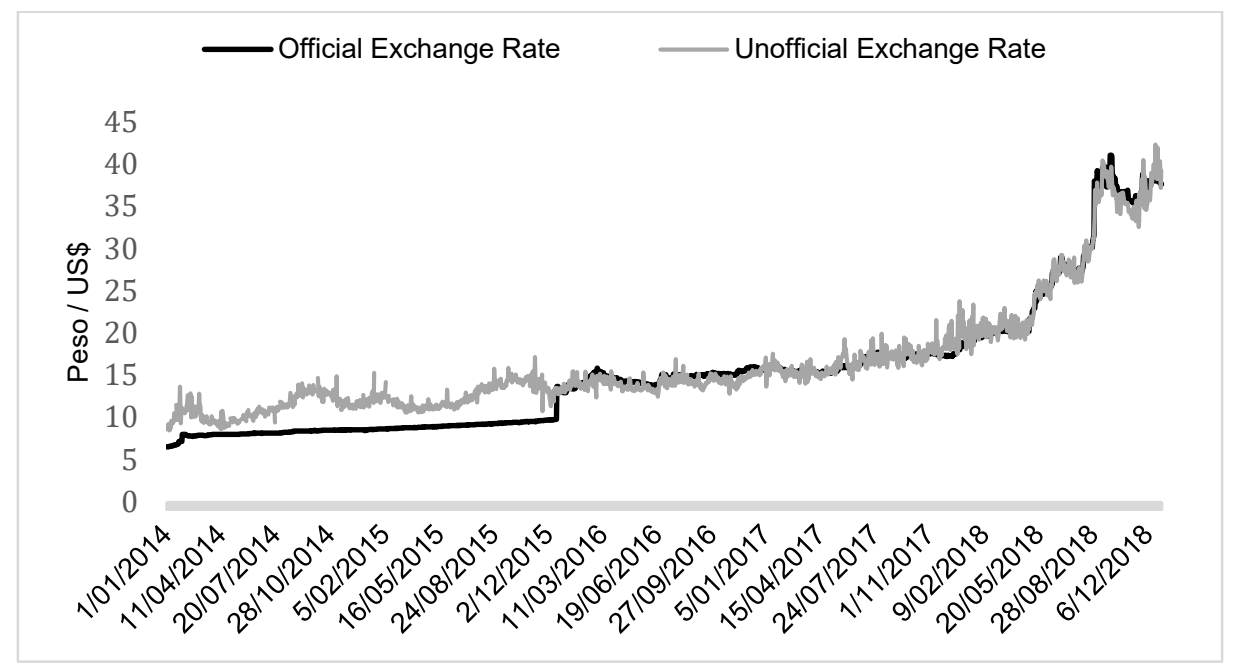

Fig. 1. Argentinian official and unofficial exchange rates from 2014 to 2018.

On December 17 the official rate is 9.778559 pesos to US dollar, the next day the official rate is adjusted to 13.67849 pesos, a significant jump. Pieters reports that apart from the official exchange rate, a semi-official exchange rate is also reported and that tracks the Bitcoin implied rate while the official rate is a crawling peg until the adjustment on 18 December 2015. ${ }^{10}$

\section{Venezuela's Analysis}

Trading P2P on LocalBitcoins in Venezuelan bolivars has grown considerably even as hyperinflation gets worse by the day. Daily reports of a massive increase in trading in Venezuelan bolivars is not exaggerated. As can been seen in Table 5, while trading declines in the pound, peso and real in 2018, as the bitcoin price falls after the 2017 high, Bitcoin trading in the Venezuelan bolivar continues to grow. This is likely fuelled by the purchase of bitcoins outside of Venezuela in any currency and redeemed in Venezuela, for bolivars, at a rate that keeps up with inflation, as well as Venezuelans buying bitcoins at any price as their own currency continues to decline each day.

Table 5. Bitcoins Traded: 2014 - 2018

\begin{tabular}{ccccccc}
\hline Year & $\begin{array}{c}\text { UK } \\
\text { Pounds Sterling }\end{array}$ & $\begin{array}{c}\text { Brazilian } \\
\text { Real }\end{array}$ & $\begin{array}{c}\text { Argentinian } \\
\text { Peso }\end{array}$ & $\begin{array}{c}\text { Venezuelan } \\
\text { Bolivar } \\
\text { Fuerte (VEF) }\end{array}$ & $\begin{array}{c}\text { Venezuelan } \\
\text { Bolivar } \\
\text { Soberano (VES) }\end{array}$ & $\begin{array}{c}\text { Venezuelan } \\
\text { Bolivar } \\
\text { Total }\end{array}$ \\
\hline 2014 & 125,118 & 985 & 2,014 & 204 & & 204 \\
2015 & 226,113 & 3,031 & 6,240 & 2,063 & & 2,063 \\
2016 & 162,638 & 4,785 & 4,336 & 8,605 & & 8,605 \\
2017 & 100,888 & 5,732 & 1,638 & 21,728 & & 21,728 \\
2018 & 36,038 & 2,858 & 1,275 & 15,296 & 21,337 & 36,633 \\
\hline
\end{tabular}

It is important to adjust for an expected premium when using LocalBitcoins P2P trading when calculating Venezuela's unofficial exchange rate from 2014 to 2018. Using Eq. (2) with 
premiums of $3 \%$ and $7 \%$, the unofficial exchange rate is calculated for the entire period and as can be seen in Table 6 it increases dramatically from January 2014 through to December 2018. Trading from 20 August 2018 is restated in VEF, for ease of comparison. The $3 \%$ is a conservative estimate of the LocalBitcoins' premium and the 7\% is similar to two other South American currencies. ${ }^{13,14}$

In five years, the unofficial exchange rate has gone from 85-89 bolivars to the US dollar to over 80 million. It is unbelievable that the government persists in an exchange rate of 10 $\mathrm{VEF} / \mathrm{US} \$$ until May 2018 while the unofficial rate reaches over 827,000 VEF/US\$. Table 6 contains details of the estimates of unofficial exchange rates using $3 \%$ and $7 \%$ premiums, the official exchange rate and details on the days when the government changed its policy.

Table 6. Venezuela: Official and Unofficial Exchange Rates: 2014 - 2018

\begin{tabular}{ccccc}
\hline As at & $\begin{array}{c}\text { Unofficial Ex. rate } \\
\text { VEF / US } \$ 1 \\
\text { 3\% Premium }\end{array}$ & $\begin{array}{c}\text { Unofficial Ex. rate } \\
\text { VEF / US } \$ 1 \\
\text { 7\% Premium }\end{array}$ & $\begin{array}{c}\text { Official } \\
\text { Exchange Rate } \\
\text { VEF/US } \$ 1\end{array}$ & $\begin{array}{c}\text { IMF Exchange } \\
\text { Rate* } \\
\text { (based on the CPI) }\end{array}$ \\
\hline 29 Jan 2014 & 89.3 & 85.6 & 6.3 & 103.2 \\
31 Dec 2014 & 189.3 & 181.5 & 6.3 & 133.0 \\
31 Dec 2015 & 756.4 & 725.19 & 6,3 & 774.9 \\
31 Dec 2016 & $2,949.0$ & $2,827.4$ & 6.3 & \\
17 Feb 2017 & $3,761.3$ & $3,606.2$ & 6.3 & \\
18 Feb 2017 & $3,791.1$ & $3,634.8$ & 10.0 & \\
31 Dec 2017 & $118,309.3$ & $113,430.6$ & 10.0 & \\
9 May 2018 & $827,907.2$ & $793,766.7$ & 10.0 & \\
10 May 2018 & $838,643.0$ & $804,059.8$ & $70,074.1$ & \\
31 Dec 2018 & $83,611,979.0$ & $80,164,062.0$ & $63,658,450.0$ & \\
\hline
\end{tabular}

* Source: IMF Exchange Rates for the Republic Bolivariana de Venezuela at data. imf .org/regular. aspx? key=61545850.

The IMF estimates (Table 6, column 5) of the unofficial exchange rate using the Consumer Price Index (CPI) are well short of the estimate using Bitcoin trading, with estimates made public only on a yearly basis. ${ }^{15}$

Even from the start of 2014 official and unofficial exchange rates diverge. Splitting the five years into three groups depending on the official exchange rate $(6.3 ; 10$; and a managed float), it is easy to see the state of the Venezuelan bolivar. With the 3\% and $7 \%$ premium's results of the same magnitude, only the 7\% premium based rates are depicted in the following figures. Fig. 2 covers January 2014 to 17 February 2017 when the official rate is 6.3 VEF/US\$ and the unofficial rate climbs from 86 to 3,606 VEF/US\$. 
LEDGER VOL 4 (2019) 108-120

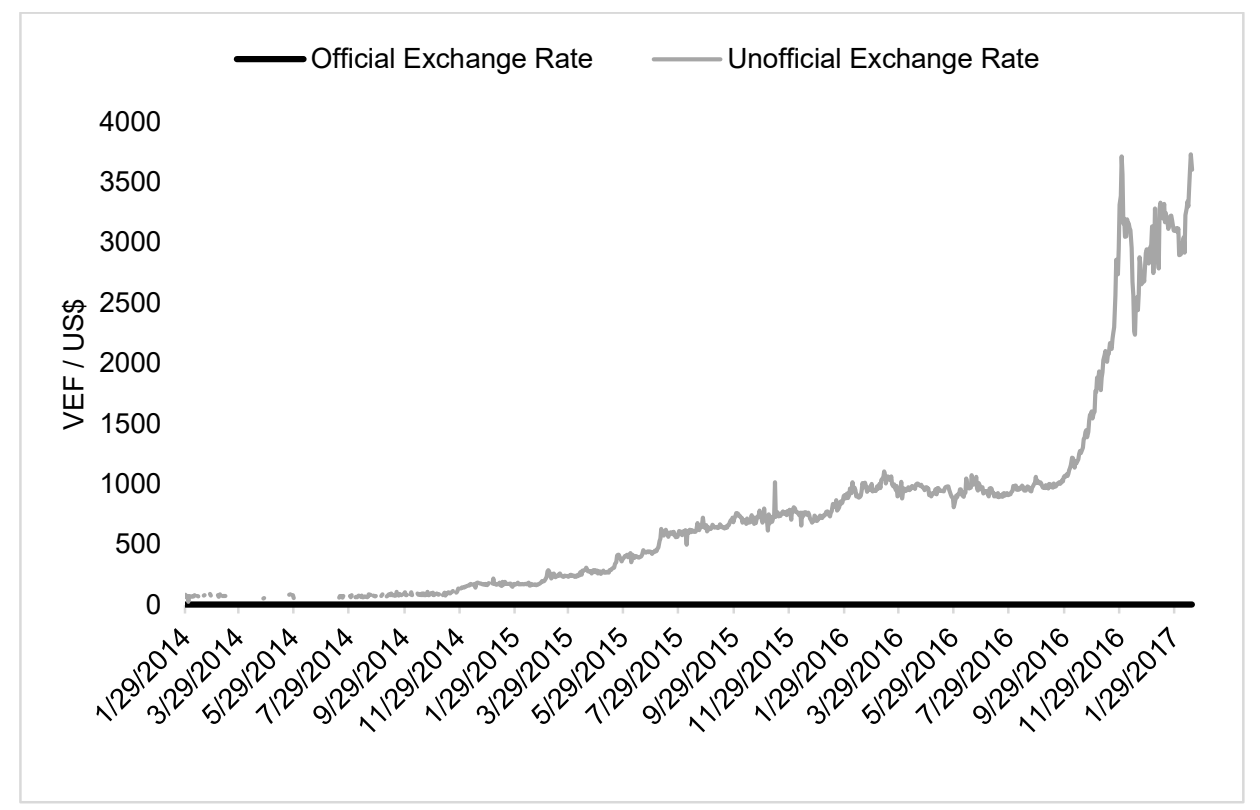

Fig. 2. Venezuelan official and unofficial exchange rates from January 2014 to 17 February 2017 when the official exchange rate is set at $6.3 \mathrm{VEF} / \mathrm{US} \$$.

Fig. 3 is the period covering the official exchange rate of $10 \mathrm{VEF} / \mathrm{US} \$$ with the unofficial rate climbing from 3,634 to 793,787 VEF/US\$. The spike on 15 February 2018 is a large purchase of bitcoins at twice the going market rate.

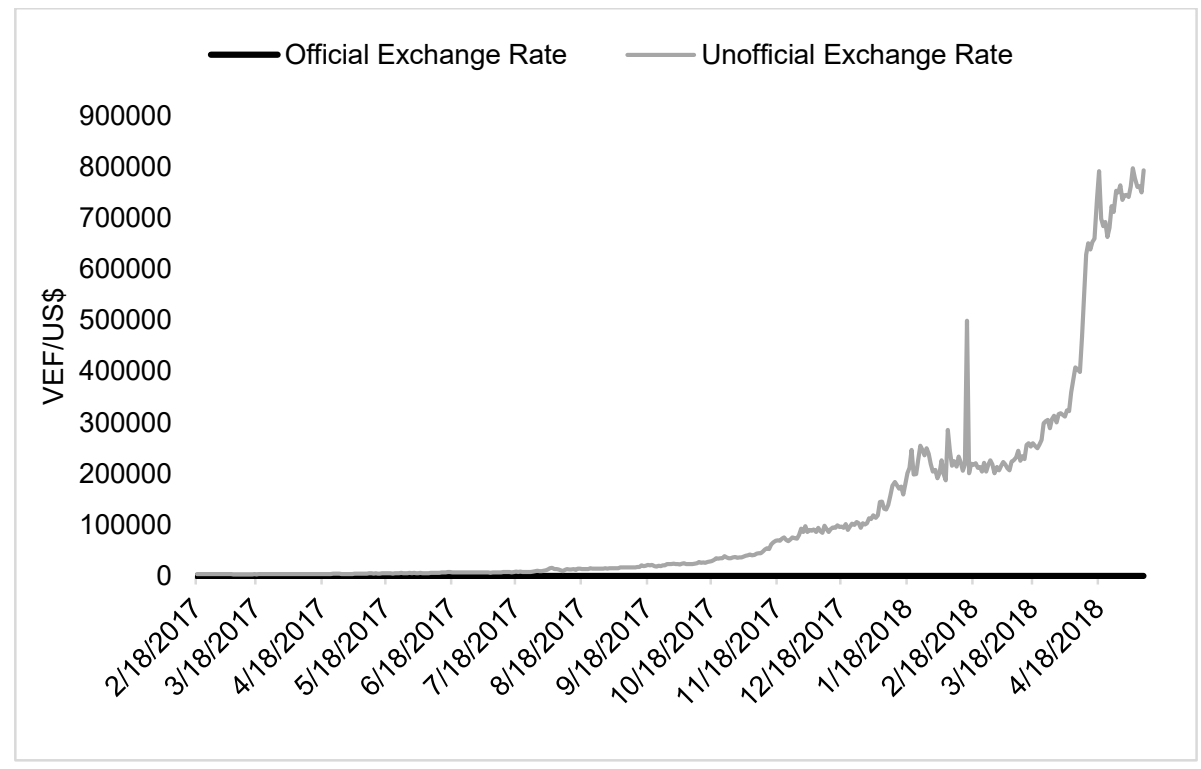

Fig. 3. Venezuelan official and unofficial exchange rates from 18 February 2017 to 9 May 2018 when the official exchange rate is set at 10.0 VEF/US\$ 
Even as the government abandons the fixed exchange rate, the official and unofficial exchange rates continue to diverge. Fig. 4 covers the period from 10 May 2018 where the official rate is now a managed float, but it still does not keep up with what is really happening to the value of the bolivar and the devaluation on 20 August 2018 (where 1 VES $=100,000$ $\mathrm{VEF}$ ) is nothing but window dressing and as can be seen in Table 7 does nothing to halt hyperinflation.

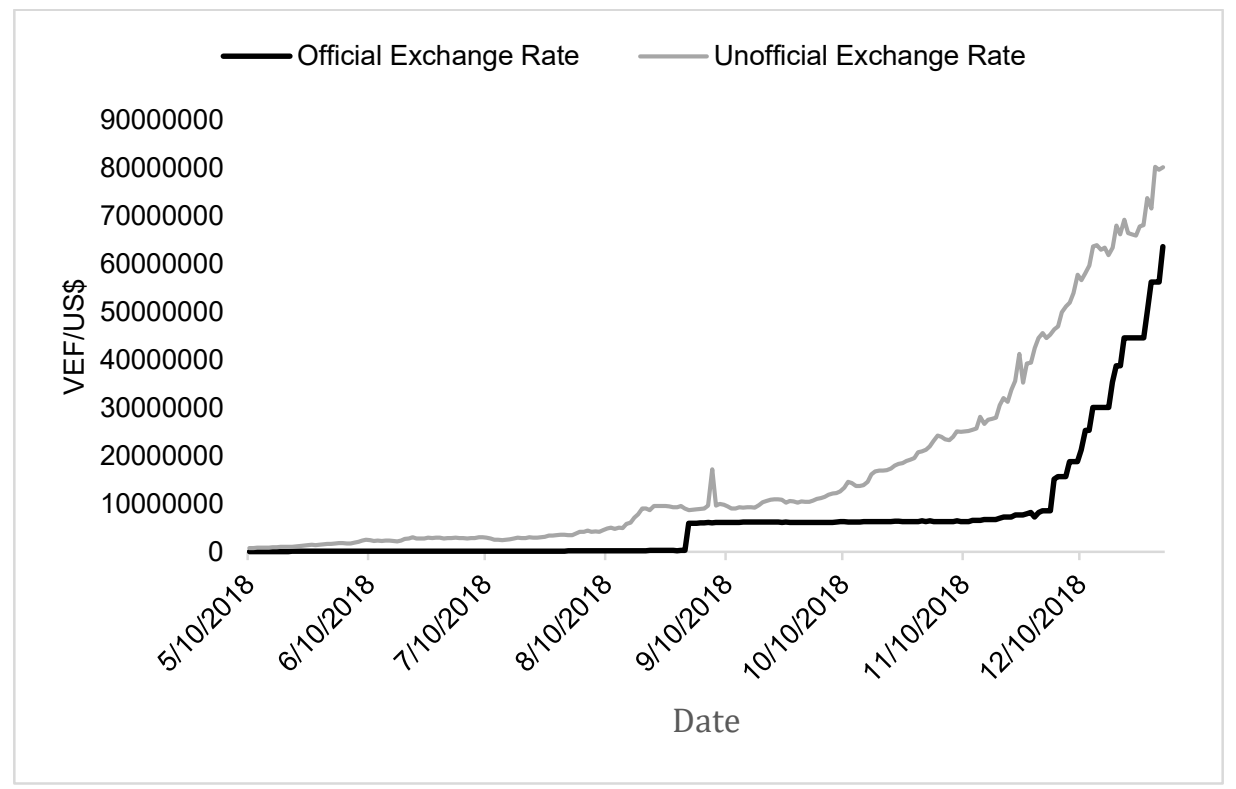

Fig. 4. Venezuelan official and unofficial exchange rates from 10 May 2018 to 31 December 2018 when the Venezuelan government moved to a managed float.

Calculating an implied inflation rate, using changes in Bitcoin's unofficial exchange rate indicates serious and increasing economic mismanagement. As can be seen in Table 7, in 2018 alone the inflation rate reaches over $70,000 \%$. The results are the same regardless of whether a premium of $3 \%$ or $7 \%$ is used, indicating that the declining value of the bolivar continues to reflect the level of economic mismanagement, leading to a catastrophic level of hyperinflation.

Table 7. Venezuela: Implied Inflation Rates

\begin{tabular}{lc}
\hline Year & Implied Inflation \\
\hline 2014 & $112 \%$ \\
2015 & $300 \%$ \\
2016 & $290 \%$ \\
2017 & $3,912 \%$ \\
2018 & $70,572 \%$ \\
\hline
\end{tabular}

With inflation rates off the scale and the exchange rate continuing its rapid increase, could this be the end of the bolivar soberano as legal tender? 


\section{Conclusion}

Bitcoin trading is a very useful tool in identifying unofficial exchange rates. It is a universal asset that should be traded at the same price in multiple currencies, allowing for the relevant exchange rate. However, supply and demand in some currencies may influence the price. In the case of Venezuela, the price at which bitcoins change hands provides evidence of significant economic mismanagement as far back as 2014. Only the lack of Bitcoin trading in 2013 and no available BPI limits the analysis. Bitcoin's unofficial exchange rates paint a picture of a country in crisis where the exchange rate and inflation increase daily. The role of Bitcoin in the crisis is critical as evidenced by the increased trading in bolivars, even as Bitcoin trading in other currencies declines. With limited or no access to US dollars the next best option is Bitcoin, which enables the transfer of funds to Venezuelan residents, outside of government control, at a time when access to a stable alternative is imperative for survival. ${ }^{16}$

Venezuela's situation changes so fast that in this case a postscript is needed to update the reader. Table 2 details the bolivar prices on 5 February 2019. LocalBitcoins data on BitcoinCharts was not available after 9 January 2019, so the February data is not included in this analysis, but the BPI is available for this date. A rough calculation of the unofficial exchange rate on 5 February 2019, using an average price of 9,161,583 VES, a BPI of US $\$ 3,420.70$ and a premium of $7 \%$ provides an unofficial exchange rate estimate of:

\section{$2,490.8 \mathrm{VES} / \mathrm{US} \$$}

$249,080,000 \mathrm{VEF} / \mathrm{US} \$$

A massive change in only five weeks from 31 December 2018 when the exchange rate is $80,164,062 \mathrm{VEF} / \mathrm{US} \$$. Hyperinflation continues to increase, with currently no end in sight.

The ability to use Bitcoin trading to gauge up to date estimates of unofficial exchange rates and implied inflation rates enables the observation of the immediate impact of any government's mismanagement and is not limited to Venezuela.

\section{Notes and References}

${ }^{1}$ Boyd, S. "Venezuelan Money Supply Is Surging at the Fastest Pace on Record." Bloomberg (5

February 2019) https: / /www . bloomberg . com/news/articles/2019-02-

05/venezuela-prints-money-at-fastest-pace-ever-in-sign-of-panic.

${ }^{2}$ For an excellent summary of the Venezuelan crises go to Wikipedia at

https://en.wikipedia.org/wiki/Crisis_in_Venezuela\#2018_and_2019_events.

${ }^{3}$ Nakamoto, S. "Bitcoin: A Peer-to-Peer Electronic Cash System.” (2008)

http://bitcoin.org/bitcoin.pdf.

${ }^{4}$ Yermack, D. "Is Bitcoin a Real Currency? An Economic Appraisal.” NBER Working paper w19747 (2013) http: / /www. nber.org/papers/w19747.

${ }^{5}$ Yelowitz, A., Wilson, M. "Characteristics of Bitcoin Users: An Analysis of Google Search Data." Applied Economics Letters 22.13 1030-1036 (2015) http: / / dx . doi.org/10 . 1080 / 13504851.2014 .995359$. 
${ }^{6}$ Bohr, J., Bashir, M. "Who Uses Bitcoin? An Exploration of the Bitcoin Community." 12th Annual Conference on Privacy, Security and Trust, PST, Institute of Electrical and Electronics Engineers Inc. 94-101 (2014) https: //doi .org/10.1109/PST. 2014. 6890928.

${ }^{7}$ Viglione, R. "Does Governance Have a Role in Pricing? Cross-Country Evidence from Bitcoin Markets." SSRN (2015) https://dx.doi.org/10.2139/ssrn.2666243.

${ }^{8} \mathrm{Li}, \mathrm{X}$., Wang, C. A. "The Technology and Economic Determinants of Cryptocurrency Exchange Rates: The Case of Bitcoin.” Decision Support Systems 95 49-60 (2017) https://doi.org/10.1016/j.dss.2016.12.001.

${ }^{9}$ Pieters, G., Vivanco, S. "Bitcoin Arbitrage and Unofficial Exchange Rates.” Working paper. (2015) http://www.ginapieters.com/uploads/1/0/2/8/10288430/bitcoin.pdf.

${ }^{10}$ Pieters, G. "Does Bitcoin Reveal New Information About Exchange Rates and Financial Integration." Federal Reserve Bank of Dallas Working paper No. 292 (2016)

https://www.dallasfed.org/-/media/documents/institute/wpapers/2016/ 0292 .pdf.

${ }^{11}$ Johnson, J. "Bitcoin Price Dynamics: The Stark Contrast Between P2P and Exchange Trading." SSRN (2019) https://ssrn.com/abstract=3290326.

${ }^{12}$ Smith, J. “An Analysis of Bitcoin Exchange Rates.” SSRN (2016) https://ssrn.com/abstract=2493797.

${ }^{13}$ Holub, M., Johnson J. "The Impact of the Bitcoin Bubble of 2017 on Bitcoin's P2P Market." Finance Research Letters 29 357-362 (2019). https : / doi .org/10.1016/ j.frl.2018.09.001.

${ }^{14}$ Holub and Johnson (see note 13, above) find that with LocalBitcoins trading, the premium paid reflects the risk of the payment being negated. In Venezuela the risk is significantly reduced as almost $100 \%$ of payments are through a specified bank. If the parties concerned use the same bank, not only does this reduce the risk but allows for the fast transfer of funds, in which case the risk would be small. As trading in bolivars has increased substantially, there is no shortage of supply or demand and therefore the incentive to trade is unnecessary. Therefore the 3\%-7\% should be enough to capture inflation.

${ }^{15}$ The calculation of the CPI, which enables the estimation of inflation is now more complicated with the inclusion of internet purchases being made in both the domestic and international markets. This adds to the complexity of maintaining a fixed basket of goods, particularly when transaction costs, such as credit card fees and postage, are now factored into the final purchase price. In addition, for Venezuela, where goods are in short supply, finding an appropriate substitute is difficult. Plus, many goods are now being sold for US dollars not bolivars. All these problems add to the delay in producing a current CPI and inflation rate. 
IMF. "Consumer Price Index (CPI) Manual, Chapter 11 Some Special Cases." (27 March 2018) https://www.imf.org/en/chapter-11-some-special-cases.ashx.

${ }^{16}$ During the period of this study there were foreign currency controls on local banks. These were put in place in 2003 with the government controlling the buying and selling of foreign currency. The exchange rate system is complex with the exchange rate depending on what is being imported and who is requesting the transaction. Limited dollars are available for purchase. These controls were not lifted until 7 May 2019. See comments in Zerpa, F., Vasquez, A. "Venezuela Lifts Controls on Banks Trading Foreign Currency." Bloomberg (7 May 2019) https://www.bloomberg.com/news/articles/2019-05-07/venezuelalifts-controls-on-banks-trading-foreign-currency; and Disilvesto, E., Howden, D. "Venezuela's Bizarre System of Exchange Rates." Mises Institute (1 July 2016) https://mises.org/library/venezuelas-bizarre-system-exchange-rates.

(cc) BY

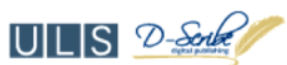

Articles in this journal are licensed under a Creative Commons Attribution 4.0 License.

Ledger is published by the University Library System of the University of Pittsburgh as part of its D-Scribe Digital Publishing Program and is cosponsored by the University of Pittsburgh Press. 